\title{
Explaining the Use of Performance Information by Public Managers: Do Task-Related Factors Matter?
}

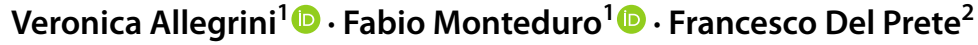

Accepted: 6 August 2021 / Published online: 3 September 2021

(c) The Author(s) 2021

\begin{abstract}
Organizational factors have frequently shown a significant influence on the use of performance information by public managers, but the study of task-related factors has been neglected. Combining insights from public administration, organizational studies, and a behavioural approach, this article investigates whether some task characteristics influence the use of performance information by public managers. Drawing on an e-mail survey on managers working in Italian medium-size municipalities, an empirical analysis was developed. Findings show that task analysability and task variability directly affect performance information use by public managers. Task interdependence shows an indirect effect on performance information use through its availability.
\end{abstract}

Keywords Performance information use $\cdot$ Task characteristics $\cdot$ Public managers · Decision-making · Organizational behaviour

\section{Introduction}

Over the last few decades, there has been an increased focus on performance management in OECD countries, particularly under public sector reforms. Governments have devoted energy and resources to measuring performance and creating performance information (Moynihan et al., 2012b). However, collecting performance information does not of itself lead to improvements. What really matters is whether and how the information is used to make better decisions and to improve public sector management (Kroll, 2015b). Moynihan and Pandey (2010) asserted

Veronica Allegrini

veronica.allegrini@uniroma2.it

Fabio Monteduro

fabio.monteduro@uniroma2.it

1 Department of Management and Law, University of Rome Tor Vergata, Via Columbia, 2, 00133 Rome, Italy

2 Department of Experimental Psychology, University of Granada, Granada, Spain 
that understanding managers' use of performance information is perhaps the most pressing challenge for scholars of performance management. This article studies the effect of task characteristics on performance information use (PIU) by public managers. Performance information has a variety of potential managerial uses. This article uses the categorization proposed by Moynihan (2009) and focuses on purposeful use, related to managers' use of performance information in decisionmaking and problem-solving. Within the public sector literature, there is a clear assumption that PIU is an organizational behaviour (Kroll \& Vogel, 2014; Kroll, 2014, 2015a; Moynihan \& Pandey, 2010; Moynihan et al., 2012a, b; Tantardini \& Kroll, 2015). It is therefore discretionary and is influenced by environmental and organizational context and individual characteristics (Moynihan \& Pandey, 2010). Scholars have been interested in understanding which factors foster this behaviour in the last two decades (see Kroll [2015b] and Cepiku [2016] for a detailed review of previous literature). The main influencing factors found in previous studies can be distinguished between factors that are environmental, organizational and individual (Kroll, 2015b). Organizational variables have more often been shown to have a significant influence on the use of performance information in decision-making by public managers (Tantardini \& Kroll, 2015). However, the study of task-related factors has been neglected. Among behavioural studies, Herbert Simon's work showed the importance of the task in shaping human behaviour in organizations (Newell \& Simon, 1972; Simon, 1997; Simon \& Reed, 1976). The psychological literature also agrees that the nature of the task is an important determiner of behaviour (Hackman, 1969). Structure and technology are particularly important in influencing behaviour in organizations (Berger \& Cummings, 1975; Blankenship \& Miles, 1968; Jones, 1984; Oldham \& Hackman, 1981; Porter \& Lawler, 1965). Studies on private sector accounting have also investigated the importance of organization technology and structure in the design and use or usefulness of management control systems in decision-making (Chenhall, 2003). There is a shortage of studies in the public field, but public and private management are similar in many important respects (Boyne, 2002), including decision-making (Simon, 1997). This article therefore adopts a behavioural approach to answer to the question: do task characteristics have an influence on PIU by public managers? In line with previous studies on factors shaping behaviour of organizational participants, task technology and task interdependence have been considered as possible determinants of PIU by public managers.

A stream of literature using a behavioural approach to study performance management has developed rapidly in the last few years (Hong, 2019, 2020; Kroll, 2015a). Some scholars have suggested that applying insights from behavioural science to the study of public administration is essential to generate impactful research (Battaglio et al., 2019). Like in Hong (2019), the article uses the term behavioural to refer to the bounded rationality view of organizational decision-making in the tradition of Simon (1997). The behavioural approach used here is therefore narrower than the approach generally used in the field of behavioural public administration and follows the recommendation to take public administration literature back to its Simonean roots (Roberts \& Wernstedt, 2019).

To answer the research question, an empirical analysis of a sample of public managers working in Italian municipalities has been developed using structural equation 
modelling. This approach is popular in social and behavioural sciences and allowed us to consider indirect relationships between task characteristics and PIU.

The article starts by defining the theoretical foundations for the work and deriving the study hypotheses. The following sections explain the research method before reviewing the results. The final sections include a critical discussion of the findings and the implications of the paper.

\section{Organizational Technology}

Scholars are unanimous in agreeing that organizational technology is an important variable in the study of organizations (Daft, 2007; Gillespie \& Mileti, 1977; Lee et al., 2010). From the 1950s to the 1980s, organizational technology attracted attention from sociologists and management scholars and was often studied as a factor influencing workers' behaviour and attitudes (Dubin, 1958; Sayles, 1958; Scott et al., 1956).

Woodward (1965) discussed the role of managers and suggested that more complex technology requires that managers approach their problems more intellectually and less emotionally. She later recognized that some aspects of organizational structure and behaviour can be explained by reference to the nature of the task, such as uncertainty and unpredictability (Woodward, 1970).

A stream of research on organizational technology at a task level was initiated by Perrow (1967). Two aspects of technology were thought relevant: the number of exceptional cases encountered in the work, or the task variability, and the nature of the search process that is undertaken by the individual when exceptions occur, or the level of problem analysability. Task variability and analysability can be combined in a single continuous dimension of routineness and can influence different components of task structure, that is control and coordination. Perrow (1967) drew on the work of March and Simon (1958) to develop a concept of technology based on the knowledge used in the workflow (Hickson et al., 1969) and he focused on the problem-solving activity.

Perrow's framework has been very influential in subsequent literature. Some scholars have related the variety and analysability of the work-unit activities with participants' information processing behaviour (Daft \& Macintosh, 1981). Another refinement (Abernethy \& Brownell, 1997; Chong, 1996; Van de Ven et al., 1976) used Perrow's dimensions of variability and analysability of the work to measure task uncertainty and assess its impact on coordination modes, managerial performance and accounting, behaviour and personnel control.

Some previous studies have seen technology as unidimensional, representing the concept by a dichotomy of routine-nonroutine (see for example Lee et al., [2010]). These dichotomies are useful in preliminary analysis, but must now be viewed as conceptually inadequate. Technology has to be viewed as a complex variable with multiple dimensions, each representing different aspects (Mileti et al., 1978). This suggests that researchers should operationalize the dimensions of both task analysability and task variability from Perrow's framework. The identified dimensions are all different aspects of the same phenomenon, but they can vary independently 
and may have distinctive influences on participants' behaviour (Daft \& Macintosh, 1981). This study therefore incorporates the multidimensional aspects of organizational technology by considering the two dimensions of task variability and task analysability from Perrow's (1967) conception of technology.

\section{Task Variability}

Task variability is the number of exceptional cases encountered in the work, that is, the degree to which stimuli are perceived as familiar or unfamiliar. It therefore describes the degree of familiarity or novelty encountered during the work activity (Perrow, 1967, 1970). When variability is low, workers' understanding of the work activity is likely to be fairly comprehensive. Few problems or unexpected situations will arise, and task execution can easily be pre-planned. In March and Simon's words, when a stimulus has been experienced repeatedly in the past, the response will be highly routinized. The stimulus will evoke a well-known situation and a set of defined possible responses (March \& Simon, 1958). Participants make extraordinary decisions infrequently. They have all the information required to make ordinary decisions, mainly based on personal past experience, and seldom need additional information. When they do, the search is focused on a small number of predictable problems. However, when task variability is high, participants frequently deal with unfamiliar, novel or unexpected stimuli and task execution is difficult to pre-plan (Daft \& Macintosh, 1981; March \& Simon, 1958; Perrow, 1970; Withey et al., 1983). Participants frequently face the need to make exceptional decisions, and often do not have the information they need to do so. When the tasks are highly variable, the knowledge required is often not found in one individual and must be gained from other individuals, other departments within the organization or external sources. Decision-makers are expected to spend a large amount of time gathering or analysing information to gain the knowledge needed to perform the task (Daft \& Macintosh, 1981). Thus:

H1: A high degree of task variability will have a positive effect on PIU.

\section{Task Analysability}

Perrow (1967) defined analysability as the nature of the search process that is undertaken by the individual when exceptions occur. It therefore describes the behaviour of workers in facing problems that arise during task performance and decisionmaking. One large component of problem-solving consists of search processes, and the search behaviour can be seen as the response at a particular stimulus (March \& Simon, 1958). The stimulus is given by the task and the nature of the problems that can arise in its performance. Analysable work processes are often characterized by a series of standard procedures, also useful in problem-solving (Daft, 2007). The problems that arise are also analysable: little reflection is required, and the solution is easily identifiable using previous knowledge and personal experience. Even if a range of problems arises, the high analysability means it is possible to make 
incremental adaptations from existing programs to address the new situation (Perrow, 1970). Analysability mainly relates to understanding of the cause-effect relations (Daft \& Macintosh, 1981). When a problem is poorly analysable, or unanalysable, these relations are not easily understandable, and participants have to spend time thinking about how to solve the problem before making decisions or performing the task (Daft \& Macintosh, 1981; Perrow, 1967, 1970; Simon, 1997). This requires search behaviour going beyond existing procedures or previously acquired personal knowledge. This is not a formal search, but relies on intuition, wisdom and previous experience of the organization (Daft, 2007; March \& Simon, 1958; Perrow, 1967). In this context, performance information based on the organizational experience heritage and highlighting the results of previous decisions and actions, can help to clarify the cause-effect relations when poorly analysable problems arise, and can therefore support decision-making. Thus:

H2: A low degree of task analysability will have a positive effect on PIU.

\section{Task Interdependence}

Task interdependence refers to the interactions among individuals in the course of taking action to get the work done and it is a dimension of organizational structure (Perrow, 1967).

The first attempts to link activities' interdependence with the usefulness of reporting systems were by March and Simon (1958). They asserted that maintaining high interdependence required an increase in the efficiency of communication required for coordination. This could be by implementing reporting systems and using feedback to coordinate.

Starting from the conceptualization of Thompson (1967), who drew on the formulation of March and Simon (1958), the study of interdependence has had a long tradition among contingency theorists. The essence of the contingency theory paradigm is that the most effective way to organize is contingent on attributes of the organizational environments (Scott, 1981). Scholars agree that task interdependence, as an element of the internal organizational environment, increases the level of coordination difficulty and has implications for information processing and implementing control systems (Chenhall, 2003; Downey \& Slocum, 1975; Galbraith, 1974; Ito \& Peterson, 1986; Thompson, 1967; Tushman \& Nadler, 1978; Van de Ven et al., 1976).

As part of the contingency approach, some scholars focused on information processing systems development as a mechanism to manage uncertainty in the work environment (Galbraith, 1974). The basic assumption of the approach is that organizations must deal with work-related uncertainty arising from various sources (Tushman \& Nadler, 1978). Uncertainty, defined as the difference between the amount of information required to perform a task and the amount of information already processed, affects the tasks of organizations. It limits organizational ability to plan and make decisions. Greater uncertainty is therefore associated with the need to process more information during task execution to achieve 
the desired performance (Galbraith, 1974). There are several possible sources of uncertainty, including task interdependence. The amount of task interdependence that exists between differentiated subunits is associated with the need for effective coordination and joint problem-solving (Tushman \& Nadler, 1978). The information processing approach suggests that a high degree of task interdependence is associated with the need to increase information processing capability during task execution. This means improving the gathering, synthesis and sharing of information in the context of organizational decision-making. Tushman and Nadler (1978) conceptualized organizations as information processing systems, whose basic function is to facilitate the effective collection, processing and distribution of information, including through the implementation of management information and control systems.

Using the same contingency view, accounting scholars began to investigate the impact of organizational features, including structure, on the design of management control systems (Gordon \& Miller, 1976; Gordon \& Narayanan, 1984; Hayes, 1977; Waterhouse \& Tiessen, 1978). Task interdependence was also studied (Chenhall \& Morris, 1986; Macintosh \& Daft, 1987). Interdependence reflects the dependence among units in the workflow in the accomplishment of their tasks, and hence the amount of coordination and feedback needed among them (Macintosh \& Daft, 1987). Higher interdependence requires more information exchange to perform the task effectively. Interdependence therefore has an important role in shaping coordination and control systems within organizations. It influences their complexity and the broadness of their scope (Chenhall, 2003). Low interdependence is associated with narrow scope control systems, focusing mainly on budget analysis (Chenhall \& Morris, 1986; Williams et al., 1990). High interdependence is associated with broad scope control systems, focusing on non-financial performance measures (Chenhall \& Morris, 1986; Hayes, 1977).

For one-person tasks, when interdependence is low, there is little need for information from or collaboration with others. However, if tasks are dependent upon the work of others for their execution or their outcome, the interdependence is high, and the need for coordination and gathering, synthesis and sharing of information increases. This suggests that higher task interdependence among subsystems should led to the use of more complex coordination and control mechanisms and more information processing than in subsystems with very little interdependence. The type of information required changes, and the focus of the control system shifts from a narrow view of financial budget to an interest in nonfinancial performance. The expectation, therefore, is that task interdependence will foster the development of performance measures, making that information available to managers.

Public management scholars agree that availability of performance information has a crucial role in determining its use (Julnes \& Holzer, 2001; Moynihan \& Ingraham, 2004; Moynihan \& Pandey, 2010; Moynihan et al., 2012b). As Moynihan and Pandey (2010) pointed out, assuming a supply-side approach to performance leads to the suggestion that provision of performance data is the key to its use. Thus:

H3: Task interdependence will have an indirect, positive effect on PIU through its influence on performance information availability. 




Fig. 1 Conceptual model

\section{Controls}

To isolate the influence of task characteristics on PIU, organizational culture was included as a control in the analyses. A demand-side view makes clear that availability is not enough and the use of performance information is also shaped by cultural norms (Moynihan \& Pandey, 2010). Previous studies have repeatedly provided evidence that an innovative or developmental culture influences PIU (Andersen \& Moynihan, 2016; Julnes \& Holzer, 2001; Moynihan \& Pandey, 2010; Moynihan et al., 2012b). Kroll (2015a) suggested that this type of organizational culture encourages openness to change and learning from mistakes. Performance information is appreciated because it fosters learning and improvement by providing additional feedback, and it therefore seems well worth including an innovative organizational culture as a control in the model.

Figure 1 shows the conceptual model of the study

\section{Method}

\section{Data Collection}

To explore whether and to what extent task characteristics influence PIU by public managers, an online survey was carried out. The participants were public managers working in Italian municipalities. These organizations have jurisdiction over a large and heterogeneous number of services. This means that municipal public managers 
share the same hierarchical level, but have very different responsibilities, requiring them to take decisions under different circumstances (Belardinelli et al., 2018). Task characteristics and managerial approaches may vary considerably between managers. This means that they are a suitable unit of analysis for this study.

Previous studies have shown that implementation of performance management in Italian local government is poor and dependent on organizational size (Grossi et al., 2016; Montesinos et al., 2013). Small municipalities are less familiar with performance measurement and management systems (Martin \& Spano, 2015). However, managers in big municipalities are under more pressure from politicians and citizens and are less prone to rely on performance information (Grossi et al., 2016). Following approaches in both national and international studies (see, for example, Folz et al. [2009]; Rivenbark \& Kelly [2003]), the analysis focused on mediumsize municipalities, with populations ranging from 25,000 to 250,000 . $^{1}$ The target population of the study was therefore public managers working in these municipalities. All available email addresses of the managers were retrieved from the municipalities' websites (a total of 2,044 valid addresses). The survey was administered between December 2018 and January 2019. The response rate of the survey was $13 \%$. This response rate is in line with previous surveys on Italian public managers (Belardinelli et al., 2018; Ditillo et al., 2015; Liguori et al., 2012). Due to few missing data, the final sample included 225 managers. The final sample mirrors the surveyed population of Italian local public managers quite well, showing very similar proportions in terms of geographical location and demographic characteristics of the municipalities in which they work.

\section{Measures}

Wherever possible, the study variables were measured using multiple items that had been tested and validated in earlier studies. All the items included in the survey were measured using a Likert-type scale ranging from 1 (strongly disagree) to 5 (strongly agree). Online Resource 1 provides more detail on the survey items.

The questionnaire was emailed in Italian, so items tested in previous studies were translated into Italian. To ensure the validity of the measures and the items, and their applicability to the Italian context, before issuing, the questionnaire was sent to some Italian experts in the field of performance management, both researchers and practitioners.

The questionnaire was then modified in the light of their feedback.

The use of performance information by public managers is considered as multidimensional, so a multi-item measure was used (as, for example, in Julnes \& Holzer, [2001]; Moynihan \& Lavertu, [2012]) instead of a single-item one (as, for example, in Moynihan \& Pandey, [2010]). The variable measured the frequency of use of information related to output, efficiency, outcome, quality of services provided by the municipality and satisfaction of users and citizens with municipal services.

\footnotetext{
1 Out of 7,960 Italian municipalities ( $1^{\text {st }}$ January 2018), 385 had more than 25,000 and less than 250,000 inhabitants.
} 
These categories are part of the common vocabulary in the public sector. However, to ensure common understanding, managers were provided with some explanations and a number of representative examples before presenting the questions. In line with Julnes and Holzer (2001), each question asked for answers to various categories of use. Following most previous studies (Julnes \& Holzer, 2001; Kroll \& Moynihan, 2015), PIU was then modelled as a single variable, by estimating the average of the scores for individual items.

As in previous research, this study was based on self-reported information, that is, managers reported on their own use. This method raises the possibility of upward response bias, but it was considered the most suitable for a study using a behavioural approach (Moynihan \& Pandey, 2010). Some reversed items were also used in the questionnaire to try to limit the phenomenon.

Performance information availability was measured using an index of five items, and its score ranged from low to high availability. The measure of task variability was an index of four items and its score also ranged from low to high. Task analysability was measured by three items and its score ranged from high to low. Task interdependence was operationalized by using four items with scores ranging from low to high. Finally, innovative culture was measured using four items with scores ranging from less to more innovative. The operationalization for all the variables can be found in Online Resource 1.

\section{Data Analysis and Results}

To test the study hypotheses, the pattern of relationships between variables (Fig. 1) was investigated using structural equation modelling constructed using LISREL 8.80. This method is particularly suitable for exploring indirect relationships between latent variables because it allows mediation to be included in the analysis (Williams et al., 2009). In this study, the interest is in estimating the effect of task interdependence on PIU through the mediating role of performance information availability.

The results of the structural model are shown in Fig. 2. They suggest that the pattern of relationships found in the data are consistent with the conceptual model. In support of $\mathrm{H} 1$, task variability increased PIU in decision-making by public managers $(\beta=0.13, p<0.05)$. Support was also found for $\mathrm{H} 2$, because a low degree of task analysability had a positive effect on PIU $(\beta=0.12, p<0.05)$. Finally, in line with $\mathrm{H} 3$, task interdependence increased performance information availability $(\beta=0.32$, $p<0.05)$, which in turn increased use $(\beta=0.65, p<0.05)$. In line with expectations, an innovative organizational culture seemed to have a role in influencing managerial behaviour $(\beta=0.26, p<0.05)$.

The overall model fit was good. As recommended by Williams et al. (2009), several indices were considered to judge the model. The model chi-square $\left(\chi^{2}\right)$ was significant at $\mathrm{p}<0.001$ and the ratio between model chi-square and degrees of freedom $\left(\chi^{2} / d f\right)$ was 1.69 (i.e., lower than the typical critical value of 2$)$. The Root Mean Square Error of Approximation (RMSEA =0.055) was much lower than the usual critical value of 0.08 and also lower than the more stringent critical value for 


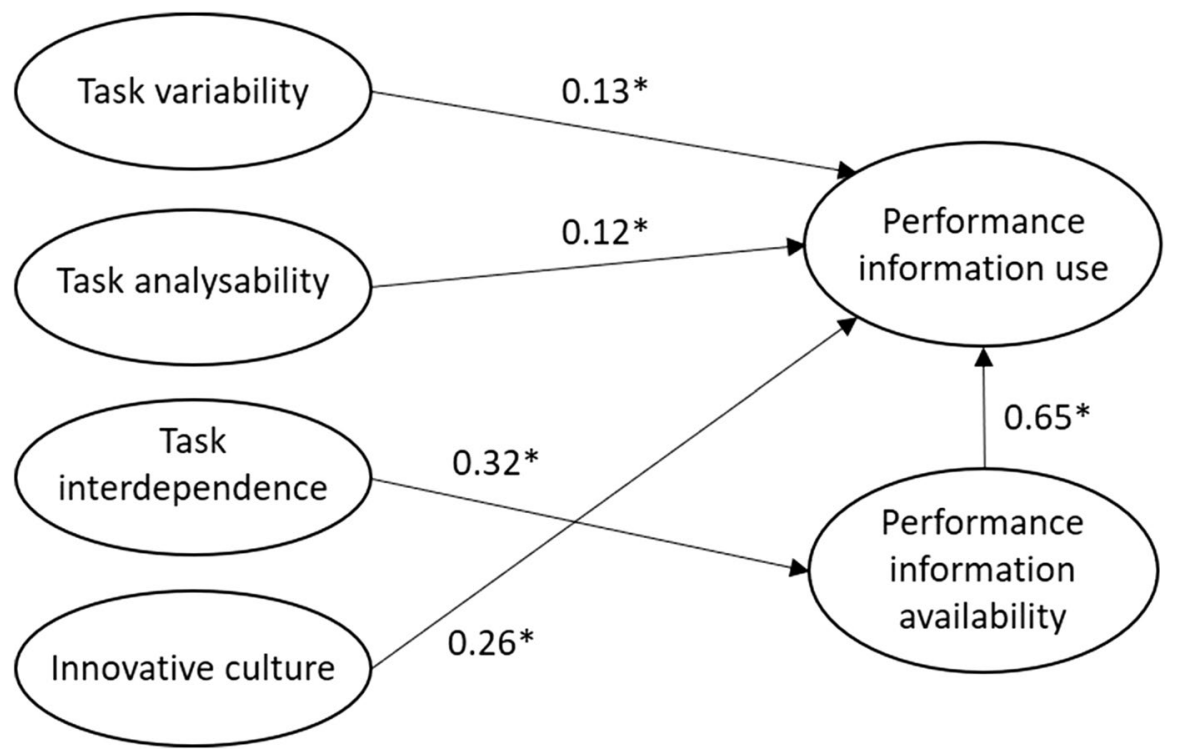

Fig. 2 Results of structural equation model

categorical data of 0.06. The Comparative Fit Index $(\mathrm{CFI}=0.94)$ was greater than 0.90 and the Standardized Root Mean Residual $(\mathrm{SRMR}=0.075)$ was less than $0.1 .^{2}$

\section{Discussion}

The central goal of this study was to understand the effect of task characteristics on the purposeful use of performance information by public managers. Overall, the results of the analysis confirm the expectation that task characteristics help to shape PIU among Italian municipal managers. In line with the hypotheses, task variability and task analysability had a direct effect on the extent of PIU in decision-making. Task interdependence also had a substantial effect on the implementation of performance measurement and reporting systems and, through this relationship, an indirect effect on PIU by public managers.

The explanation of these results is supported by a behavioural approach. Like in Hong (2019), the term behaviour is here used to describe the bounded rationality view of organizational decision-making in the tradition of Simon (1997).

The behavioural model of choice is based on the idea that decision-makers exist within a bounded rationality. They therefore lack perfect information and must seek and process information to find a satisfactory alternative (Hong, 2019; Jones, 2003; Simon, 1997). In modern society, there is no lack of information, but there may be a shortage of time and the capacity to find relevant information. Organizations should

2 This standard was drawn from Kline (2005) and Hooper, Coughlan, and Mullen (2008). 
design effective information-processing systems to help decision-makers to select useful information. Information does not have to be processed just because it is there (Simon, 1997) and the allocation of attention is a major key to understanding processing (Jones, 2003). Capacity, time and attention are scarce resources, so processing capacity must be allocated to the most important or critical decision tasks. Stimuli are used to direct attention and set priorities among tasks. Jones $(2003,406)$ asserted that, 'in modern complex environments, neither individuals nor organizations respond simply to stimuli. They must attend, prioritize and select an appropriate response'. Much of the behaviour in organizations is task-oriented, so the main stimuli influencing decision-makers' behaviour and setting the priority for information processing come from the characteristics of the tasks themselves.

Task variability and task analysability were studied. Variability was defined as the number of exceptional cases encountered in the work, or the degree to which stimuli are perceived as familiar or unfamiliar (Perrow, 1967). When a stimulus is perceived as familiar, it evokes a well-known situation and a set of defined possible alternative responses. The choice of satisfactory alternatives is based on decision-makers' personal past experience and they have little need to seek additional information. However, when task variability is high and the stimuli are unfamiliar, decision-makers face exceptional decisions and often do not have the information they need. They therefore need to spend more time gathering or analysing information, to gain the required knowledge and find a satisfactory alternative. Task analysability is mainly about understanding the cause-effect relations. Analysable work processes are often characterized by a series of standard procedures, also useful in problem-solving. Little reflection is required, and the cause-effect relation of the identified solution is easily identifiable from previous knowledge and personal experience. When a problem is poorly analysable, the cause-effect relations are not easily understandable, and considerable processing of information is needed before making decisions or performing the task. The search is not formal, but relies on intuition, wisdom and previous experience of the organization. The degree of variability and analysability of a task therefore have an impact on the allocation of the processing information capacity, both theoretically and in the study.

There is a question why performance information may be more useful than other information. The theory of bounded rationality developed by Simon suggests that the manager acts as a so-called 'satisficer' in the decision process (Tummers, 2020). Managers cannot evaluate all the potential alternatives so they look for a course of action that is "good enough", rather than search for the best alternative (Simon, 1997).

What is considered a satisfactory alternative depends both on the aspiration level (Simon, 1955) and on the expected consequences (Simon, 1997). A primary influence on choice is knowledge about the possible consequences. Individuals cannot, of course, know exactly what consequences will follow from behaviour, but they can form expectations of future consequences based on information about the existing situation and the consequences of past decisions (Simon, 1997). Whether an alternative is considered satisfactory also depends on the aspiration level, or the level of performance or outcomes desired by the organization. This in turn depends on several factors, including the performance history of the organization (Hong, 
2019). Performance information forms the expectation on the cause-effect relations of the possible choice alternatives and anchors the aspiration levels. Information on the past performance of the organization is therefore likely to be used by managers during decision processes.

The last task characteristic considered was interdependence. Organizations are cooperative systems, and their members are expected to orient their behaviour to accomplish organizational objectives. This leads to a certain degree of task interdependence and leaves the problem of coordinating decision-makers' behaviour, providing each one with knowledge about the behaviour of others to support their decisions (Simon, 1997). The capacity of an organization to manage high interdependence is limited in part by its capacity to handle the communication required for coordination: when communication within the organization is more efficient, there is a greater tolerance for interdependence. Increasing interdependence may require a change in the type of coordination and the implementation of reporting systems. High interdependence requires coordination involving the transmission of performance information during the decision process. This is also known as coordination by feedback (March \& Simon, 1958) or coordination by mutual adjustments (Thompson, 1967). The implementation of reporting systems increases the efficiency of communication, and consequently the tolerance for interdependence, by making it possible to communicate large amounts of information using a synthetic and standardized language (March \& Simon, 1958). In other words, when interdependence is higher, a greater level of information exchange is required to effectively perform the task. For interdependent tasks, the decision output of one unit becomes the decision input of another. This means that an important factor in the decisionmaking process is knowledge of the decisions taken by other units and their consequences. Performance information reporting systems are therefore likely to be useful in helping decision-making in an organizational environment characterized by high task interdependence.

\section{Conclusion}

In the context of administrative reforms, a focus on performance management has been an important trend and public managers are required to use performance information in decision-making. Moynihan and Hawes (2012) noted that administrative reforms outline the desirable behaviour of public servants but pay little attention to which factors generate the required type of purposeful behaviour. A broad stream of literature on factors that foster or constrain PIU by public managers has therefore developed. This study develops those discussions by focusing on task characteristics. Its first contribution to the literature is therefore to consider the effects of factors neglected until now on the use of performance information in decision-making by public managers. In addition, considering PIU as a type of behaviour, the study has built on research on administrative behaviour to frame hypothesis and explain results. The used approach draws on the bounded rationality view of organizational decision-making and tries to bring the study of PIU closer to the tradition of Simon (1997). Using a behavioural approach, the findings provide a better understanding 
of the mechanisms by which variability, analysability and interdependence of tasks shape PIU by public managers. This influence is basically modelled as stimulus-response and this interpretation could be used in two ways in future research: to study how public servants modify their behaviour in response to other characteristics of the task environment, and to study other effects of task variability, analysability and interdependence as stimuli for decision-makers' behaviour.

The study also has implications for managers. The findings suggest that the use of performance information could help to manage high variability and low analysability of tasks in decision-making. It could form expectations about the cause-effect relations of the possible choice alternatives and anchor aspiration levels to determine a satisfactory choice alternative. The use of performance information can also help in coordinating decision-makers' behaviours where there is task interdependence. The decision output of one unit will become the decision input of another, and the level of information exchange required to perform tasks effectively increases with interdependence. Managers can benefit from this awareness. This study also shows that public organizations should invest in vertical information systems, particularly performance measurement and reporting systems, to help managers with difficult or interdependent tasks. Implementing these systems does not lead to improvements in itself, because what matters is whether and how the information is used (Kroll, 2015b; Moynihan \& Pandey, 2010). However, both previous literature and the results of this study suggest that availability of performance information has a role in determining its use.

Last, from policy-makers' perspective, it is common practice to introduce new legal requirements to improve performance measurement and reporting, especially in countries where the public sector has a strong legalistic tradition and bureaucratic culture, such as Italy (Marcuccio \& Steccolini, 2009). A mandatory approach is adopted in the belief that this will require organizations to change their behaviour. The risk, however, is that organizations adopt a formalistic approach and simply comply with requirements (Martí et al., 2012; Neale \& Anderson, 2000). However, policymakers should share information among public managers about the benefits of using a performance management system and, above all of using performance information in decision-making. If this knowledge was internalized, managers might be less inclined to adopt a formalistic approach and more motivated to change their behaviour.

The study has some limitations. The analysis was cross-sectional. It may be helpful to repeat the study in future to provide a longitudinal analysis of the variation in PIU when the degree of task variability, analysability and interdependence vary over time. Then, the analysis was on data from Italian municipal managers, so caution is needed in generalizing the findings to other levels of government or other regions. Additional research on the effects of task characteristics on PIU is needed to determine the generalizability of findings.

Supplementary Information The online version contains supplementary material available at https://doi. org/10.1007/s11115-021-00556-y.

Funding Open access funding provided by Università degli Studi di Roma Tor Vergata within the CRUICARE Agreement. 


\section{Declarations}

Ethical approval The study does not need ethical approval.

Informed Consent Informed consent was obtained from all individual participants included in the study.

Conflicts of interest The authors have no conflicts of interest to declare.

Open Access This article is licensed under a Creative Commons Attribution 4.0 International License, which permits use, sharing, adaptation, distribution and reproduction in any medium or format, as long as you give appropriate credit to the original author(s) and the source, provide a link to the Creative Commons licence, and indicate if changes were made. The images or other third party material in this article are included in the article's Creative Commons licence, unless indicated otherwise in a credit line to the material. If material is not included in the article's Creative Commons licence and your intended use is not permitted by statutory regulation or exceeds the permitted use, you will need to obtain permission directly from the copyright holder. To view a copy of this licence, visit http://creativecommons.org/licen ses/by/4.0/.

\section{References}

Abernethy, M. A., \& Brownell, P. (1997). Management control systems in research and development organizations: The role of accounting, behavior and personnel controls. Accounting, Organizations and Society, 22(3-4), 233-248.

Andersen, S. C., \& Moynihan, D. P. (2016). How leaders respond to diversity: The moderating role of organizational culture on performance information use. Journal of Public Administration Research and Theory, 26(3), 448-460.

Battaglio, R. P., Jr., Belardinelli, P., Bellé, N., \& Cantarelli, P. (2019). Behavioral public administration ad fontes: A synthesis of research on bounded rationality, cognitive biases, and nudging in public organizations. Public Administration Review, 79(3), 304-320.

Belardinelli, P., Bellé, N., Sicilia, M., \& Steccolini, I. (2018). Framing effects under different uses of performance information: An experimental study on public managers. Public Administration Review, 78(6), 841-851.

Berger, C. J., \& Cummings, L. L. (1975). Organization Structure, Attitudes, and Behavior: Where Are We Now?. In Academy of Management Proceedings, 176-178. Academy of Management.

Blankenship, L. V., \& Miles, R. E. (1968). Organizational structure and managerial decision behavior. Administrative Science Quarterly, 106-120.

Boyne, G. A. (2002). Public and private management: What's the difference? Journal of Management Studies, 39(1), 97-122.

Cepiku, D. (2016). Performance management in public administration. In The Routledge Handbook of Global Public Policy and Administration, 315-330. Routledge.

Chenhall, R. H. (2003). Management control systems design within its organizational context: Findings from contingency-based research and directions for the future. Accounting, Organizations and Society, 28(2-3), 127-168.

Chenhall, R. H., \& Morris, D. (1986). The impact of structure, environment, and interdependence on the perceived usefulness of management accounting systems. Accounting Review, 16-35.

Chong, V. K. (1996). Management accounting systems, task uncertainty and managerial performance: A research note. Accounting, Organizations and Society, 21(5), 415-421.

Daft, R. L. (2007). Organization theory and design. $9^{\text {th }}$ edition. Thomson South-Western.

Daft, R. L., \& Macintosh, N. B. (1981). A tentative exploration into the amount and equivocality of information processing in organizational work units. Administrative science quarterly, 207-224.

Ditillo, A., Liguori, M., Sicilia, M., \& Steccolini, I. (2015). Control patterns in contracting-out relationships: It matters what you do, not who you are. Public Administration, 93(1), 212-229. 
Downey, H. K., \& Slocum, J. W. (1975). Uncertainty: Measures, research, and sources of variation. Academy of Management Journal, 18(3), 562-578.

Dubin, R. (1958). Working union-management relations: The sociology of industrial relations. Prentice-Hall.

Folz, D. H., Abdelrazek, R., \& Chung, Y. (2009). The adoption, use, and impacts of performance measures in medium-size cities: Progress toward performance management. Public Performance \& Management Review, 33(1), 63-87.

Galbraith, J. R. (1974). Organization design: An information processing view. Interfaces, 4(3), 28-36.

Gillespie, D. F., \& Mileti, D. S. (1977). Technology and the study of organizations: An overview and appraisal. Academy of Management Review, 2(1), 7-16.

Gordon, L. A., \& Miller, D. (1976). A contingency framework for the design of accounting information systems. Accounting, Organizations and Society, 1(1), 59-69.

Gordon, L. A., \& Narayanan, V. K. (1984). Management accounting systems, perceived environmental uncertainty and organization structure: An empirical investigation. Accounting, Organizations and Society, 9(1), 33-47.

Grossi, G., Reichard, C., \& Ruggiero, P. (2016). Appropriateness and use of performance information in the budgeting process: Some experiences from German and Italian municipalities. Public Performance \& Management Review, 39(3), 581-606.

Hackman, J. R. (1969). Effects of task factors on job attitudes and behavior: A symposium: IV. Nature of the task as a determiner of job behavior. Personnel Psychology, 22(4), 435-444.

Hayes, D. C. (1977). The contingency theory of managerial accounting. Accounting review, 22-39.

Hickson, D. J., Pugh, D. S., \& Pheysey, D. C. (1969). Operations technology and organization structure: An empirical reappraisal. Administrative science quarterly, 378-397.

Hong, S. (2019). A behavioral model of public organizations: Bounded rationality, performance feedback, and negativity bias. Journal of Public Administration Research and Theory, 29(1), 1-17.

Hong, S. (2020). Performance Management Meets Red Tape: Bounded Rationality, Negativity Bias, and Resource Dependence. Public Administration Review, 80(6), 932-945.

Hooper, D., Coughlan, J., \& Mullen, M. R. (2008). Structural equation modelling: Guidelines for determining model fit. Electron J Bus Res Methods, 6, 53-60.

Ito, J. K., \& Peterson, R. B. (1986). Effects of task difficulty and interunit interdependence on information processing systems. Academy of Management Journal, 29(1), 139-149.

Jones, B. D. (2003). Bounded rationality and political science: Lessons from public administration and public policy. Journal of Public Administration Research and Theory, 13(4), 395-412.

Jones, G. R. (1984). Task visibility, free riding, and shirking: Explaining the effect of structure and technology on employee behavior. Academy of Management Review, 9(4), 684-695.

Julnes, P. D. L., \& Holzer, M. (2001). Promoting the utilization of performance measures in public organizations: An empirical study of factors affecting adoption and implementation. Public Administration Review, 61(6), 693-708.

Kline, R. B. (2005). Principles and Practice of Structural Equation Modeling (2nd Edition ed.). The Guilford Press.

Kroll, A. (2014). Why performance information use varies among public managers: Testing managerrelated explanations. International Public Management Journal, 17(2), 174-201.

Kroll, A. (2015a). Explaining the use of performance information by public managers: A planned-behavior approach. The American Review of Public Administration, 45(2), 201-215.

Kroll, A. (2015b). Drivers of performance information use: Systematic literature review and directions for future research. Public Performance \& Management Review, 38(3), 459-486.

Kroll, A., \& Moynihan, D. P. (2015). Does training matter? Evidence from performance management reforms. Public Administration Review, 75(3), 411-420.

Kroll, A., \& Vogel, D. (2014). The PSM-leadership fit: A model of performance information use. Public Administration, 92(4), 974-991.

Lee, J. W., Rainey, H. G., \& Chun, Y. H. (2010). Goal ambiguity, work complexity, and work routineness in federal agencies. The American Review of Public Administration, 40(3), 284-308.

Liguori, M., Sicilia, M., \& Steccolini, I. (2012). Some like it non-financial... Politicians' and managers' views on the importance of performance information. Public Management Review, 14(7), 903-922.

Macintosh, N. B., \& Daft, R. L. (1987). Management control systems and departmental interdependencies: An empirical study. Accounting, Organizations and Society, 12(1), 49-61.

March, J. G., \& Simon, H. A. (1958). Organizations. Wiley. 
Marcuccio, M., \& Steccolini, I. (2009). Patterns of voluntary extended performance reporting in Italian local authorities. International Journal of Public Sector Management, 22(2), 146-167.

Martí, C., Royo, S., \& Acerete, B. (2012). The effect of new legislation on the disclosure of performance indicators: The case of Spanish local governments. International Journal of Public Administration, 35(13), 873-885.

Martin, J., \& Spano, A. (2015). From performance management to strategic local government leadership: Lessons from different cultural settings. Public Money \& Management, 35(4), 303-310.

Mileti, D. S., Gillespie, D. F., \& Morrissey, E. (1978). Technology and organizations: Methodological deficiencies and lacunae. Technology and Culture, 19(1), 83-92.

Montesinos, V., Brusca, I., Rossi, F. M., \& Aversano, N. (2013). The usefulness of performance reporting in local government: Comparing Italy and Spain. Public Money \& Management, 33(3), 171-176.

Moynihan, D. P. (2009). Through a glass, darkly: Understanding the effects of performance regimes. Public Performance \& Management Review, 32(4), 592-603.

Moynihan, D. P., \& Hawes, D. P. (2012). Responsiveness to reform values: The influence of the environment on performance information use. Public Administration Review, 72(s1), S95-S105.

Moynihan, D. P., \& Ingraham, P. W. (2004). Integrative leadership in the public sector: A model of performance-information use. Administration \& Society, 36(4), 427-453.

Moynihan, D. P., \& Lavertu, S. (2012). Does involvement in performance management routines encourage performance information use? Evaluating GPRA and PART. Public Administration Review, 72(4), 592-602.

Moynihan, D. P., \& Pandey, S. K. (2010). The big question for performance management: Why do managers use performance information? Journal of Public Administration Research and Theory, 20(4), 849-866.

Moynihan, D. P., Pandey, S. K., \& Wright, B. E. (2012a). Prosocial values and performance management theory: Linking perceived social impact and performance information use. Governance, 25(3), 463-483.

Moynihan, D. P., Pandey, S. K., \& Wright, B. E. (2012b). Setting the table: How transformational leadership fosters performance information use. Journal of Public Administration Research and Theory, 22(1), 143-164.

Neale, A., \& Anderson, B. (2000). Performance reporting for accountability purposes: Lessons, issues, future. International Public Management Journal, 3(1), 93-106.

Newell, A., \& Simon, H. A. (1972). Human problem solving\&nbsp;(Vol.104, No.9). Prentice-hall.

Oldham, G. R., \& Hackman, J. R. (1981). Relationships between organizational structure and employee reactions: Comparing alternative frameworks. Administrative Science Quarterly, 66-83.

Perrow, C. (1967). A Framework for the Comparative Analysis of Organizations. American Sociological Review, 32(2), 194-208.

Perrow, C. (1970). Organizational Analysis: A Sociological View. Tavistock Publications.

Porter, L. W., \& Lawler, E. E. (1965). Properties of organization structure in relation to job attitudes and job behavior. Psychological Bulletin, 64(1), 23-51.

Rivenbark, W. C., \& Kelly, J. M. (2003). Management innovation in smaller municipal government. State and Local Government Review, 35(3), 196-205.

Roberts, P. S., \& Wernstedt, K. (2019). Herbert Simon's Forgotten Legacy for Improving Decision Processes. International Public Management Journal, 22(4), 591-616.

Sayles, L. R. (1958). Behavior of Industrial Work Groups: Prediction and Control. Wiley.

Scott, W. R. (1981). Organizations: Rational, Natural, and Open Systems. Prentice-Hall.

Scott, W. H., Halsey, A. H., Banks, J. A., \& Lupton, T. (1956). Technical change and industrial relations: A study of the relations between technical change and the social structure of a large steelworks. Liverpool University Press.

Simon, H. A. (1955). A Behavioral model of rational choice. The Quarterly Journal of Economics, 69(1), 99-118.

Simon, H. A. (1997). Administrative behavior. (4th edition). The free press.

Simon, H. A., \& Reed, S. K. (1976). Modeling strategy shifts in a problem-solving task. Cognitive Psychology, 8(1), 86-97.

Tantardini, M., \& Kroll, A. (2015). The role of organizational social capital in performance management. Public Performance \& Management Review, 39(1), 83-99.

Thompson, J. D. (1967). Organizations in action: Social science bases of administrative theory. McGraw-Hill. 
Tummers, L. (2020). Behavioral public administration. In B. G. Peters, \& I. Thynne (Eds.), Oxford Research Encyclopedia of Public Administration. Oxford University Press.

Tushman, M. L., \& Nadler, D. A. (1978). Information processing as an integrating concept in organizational design. Academy of Management Review, 3(3), 613-624.

Van de Ven, A. H., Delbecq, A. L., \& Koenig Jr, R. (1976). Determinants of coordination modes within organizations. American Sociological Review, 322-338.

Waterhouse, J. H., \& Tiessen, P. (1978). A contingency framework for management accounting systems research. Accounting, Organizations and Society, 3(1), 65-76.

Williams, J. J., Macintosh, N. B., \& Moore, J. C. (1990). Budget-related behavior in public sector organizations: Some empirical evidence. Accounting, Organizations and Society, 15(3), 221-246.

Williams, L. J., Vandenberg, R. J., \& Edwards, J. R. (2009). 12 structural equation modeling in management research: A guide for improved analysis. Academy of Management Annals, 3(1), 543-604.

Withey, M., Daft, R. L., \& Cooper, W. H. (1983). Measures of Perrow's work unit technology: An empirical assessment and a new scale. Academy of Management Journal, 26(1), 45-63.

Woodward, J. (1965). Industrial organization: Theory and practice. Oxford University Press.

Woodward, J. (1970). Industrial organization: Behaviour and control. Oxford University Press.

Publisher's Note Springer Nature remains neutral with regard to jurisdictional claims in published maps and institutional affiliations. 